\title{
Recruiting and Retaining Quality Teachers in Mississippi through Learning and Education through Alternative Programs: LEAP
}

\author{
Matthew Boggan, Teresa Jayroe \\ Mississippi State University, USA
}

\begin{abstract}
Learning and Educating through Alternative Programs (LEAP), a five-year, multifaceted grantfunded project, works with an alternate route program of study housed at Mississippi State University in Starkville, Mississippi (U.S.), to fulfill state teacher certification requirements for highly qualified mid-career professionals and recent college graduates who did not major in education. LEAP focuses on recruiting, training, hiring, and retaining these mid-career professionals as alternate route teachers for critically understaffed positions in highneed schools throughout the state of Mississippi. The LEAP program, which serves all areas of the state through the Mississippi State University - Starkville campus and the MSU - Meridian Division of Education, aims to certify 35 new teachers per year, with a total of at least 175 over the 5-year grant period. LEAP is funded by a Transition to Teaching grant through the United States Department of Education.
\end{abstract}

\section{Introduction}

In 2009, faculty in the College of Education (COE) at Mississippi State University (MSU) Starkville and the MSU-Meridian Division of Education were awarded a Transition to Teaching grant that was funded through the United States Department of Education. This federally funded grant, Learning and Educating through Alternative Programs (LEAP), is a collaborative project with faculty and staff in MSU's COE, the Mississippi Department of Education (MDE), and a consortium of 42 high-need rural Local Education Agencies (LEAs).

\section{State of Mississippi Statistics}

The state of Mississippi, which is located in the southern part of the United States of America (U.S.) and borders the Gulf of Mexico, faces an array of problems that often make it difficult for school districts to recruit and retain sufficient numbers of qualified teachers. In 2008, the United States Census Bureau reported that Mississippi had an estimated population of 2,938,618 with approximately 555,834 of that estimated population comprised of children in the kindergarten through twelfth grade range.

Mississippi has the largest proportion of African Americans of any state in the United States, currently $37.1 \%$. The balance of the population is white (60.1\%), with a very small population of other residents (2.8\%) who are Hispanic, Asian, or Native American. Education in Mississippi is considered primarily rural, with $46 \%$ of students living in rural areas and over $50 \%$ of state education funds going to rural districts.

Why Rural Matters 2003: The Continuing Need for Every State to Take Action on Rural Education reported that the Rural School and Community Trust provided a state-by-state look at rural education and ranked Mississippi the highest among the 50 states in need of rural education attention and improvement. In 2006, per capita personal income in Mississippi was only $\$ 26,908$, the lowest of any state. In addition in 2006, the poverty rate for Mississippi was $21.3 \%$, the highest in the U.S.

According to the National Center for Children in Poverty, nearly $24 \%$ of children in Mississippi live in poverty, with $12 \%$ living in extreme poverty. Mississippi ranks among the lowest of all 50 states in levels of parental education, with fewer than $20 \%$ of parents graduating from college and $20 \%$ not completing high school. The percentage of singleparent families, over $25 \%$, is among the highest in the U.S. According to a report released in January 2009 by the Centers for Disease Control, Mississippi "now has the nation's highest teen pregnancy rate, [with 68 births per 1,000 teenage girls], displacing Texas and New Mexico for stated that in 2006 the Mississippi teen pregnancy rate was over $60 \%$ higher than the national average and had increased $13 \%$ since the year before.

These conditions severely impact Mississippi children's ability to learn and succeed in school. Scores on the National Assessment of Educational 
Progress (NAEP) and graduation rates are among the lowest in the United States. In 2007, Mississippi students scored the lowest of any state on the NAEP in both math and science [3]. Compounding these obstacles are conditions and outcomes directly attributable to policy decisions. Schools and districts operate with the second lowest instructional expenditures and the fourth lowest instructional salaries in the nation. In 2004, Mississippi was ranked last among the 50 states in academic achievement by the American Legislative Exchange Council's Report Card on Education, with the lowest average American College Testing (ACT) scores and lowest spending per pupil in the nation.

\section{Highly Qualified Teachers}

One of the most powerful factors in students' academic success is their access to well-prepared teachers. Teacher quality, which includes teacher certification status, degree in field, and participation in high-quality professional development, all have a significant impact on student outcomes [1]; [2]; [4]. Improving the quality of teaching in the classroom has the greatest impact on those students identified as most educationally at risk. Sanders and Rivers (1996) found that in some instances the effects of wellprepared teachers on student achievement are stronger than the influences of student background factors, such as poverty, language background, and minority status. Gándara and Maxwell-Jolly (2000) stated that well-qualified teachers provide a wide range of teaching strategies by: asking questions that make students think and answer fully; addressing students' learning needs and curriculum goals; making subject matter accessible to diverse groups of students; and by making rigorous learning satisfying and fun. Finally, research shows that teacher certification and/or teacher experience and preparation correlate significantly with student achievement even after factoring out the effects of student poverty [5].

Highly qualified teachers are those teachers who have earned at least a bachelor's degree, demonstrated content knowledge in each core content area he/she teaches, and do not have any waivers of the requirements for full state certification. A teacher is not considered to meet the highly qualified certification requirements if the teacher has had certification waived on an emergency, temporary, or provisional basis, including temporary out-of-state certificates, transitional certificates, temporary provisions, interim certificates, or out-of-field permits. Implementation of the No Child Left Behind Highly Qualified Teacher Requirement means that states must take action to ensure that inexperienced, unqualified, or out-of-field teachers do not teach poor or minority children at higher rates than other children.

\section{Teacher Shortage}

There is a critical shortage of highly qualified teachers across the state of Mississippi. Many teachers were teaching out of their field of certification, and many school districts were forced to fill teaching positions with non-certified personnel. In the 2007-2008 academic school year, 3.8\% of instructors in Mississippi held emergency licenses. About $6 \%$ of core classes were taught by teachers who were not considered highly qualified. In poorer districts, $11.8 \%$ of core classes were taught by teachers who were not highly qualified. As reported by the Clarion-Ledger, a state-wide newspaper, in December 2008, "With 2,397 teachers in classrooms in Mississippi on emergency licenses, the state is facing a teacher shortage that could worsen next year if even a fraction of the 6,000 veteran educators' eligible to retire actually do so.”

The state of Mississippi has attempted to alleviate teacher shortage problems by offering a number of incentives designed to attract and retain qualified teachers who will contract to teach in designated Critical Shortage Areas (CSAs). These include monetary incentives, such as scholarships and payment of tuition, fees and books for undergraduate education majors, fellowships for Master of Education and Education Specialists degree students, and moving and housing assistance grants for licensed teachers. Even with these incentives, provided under the Mississippi Critical Teacher Shortage Act of 1998, there is still a shortage of highly qualified teachers in some of the poorest and most needy school districts.

In the 2006-2007 academic school year, the state of Mississippi employed 33,494 teachers who taught 490,336 students in 1,058 schools in 152 school districts (Feistritzer, 2008). Mississippi began aggressively utilizing alternative routes for teacher preparation in 2003. In 2007, the MDE contracted with the National Center for Alternative Certification (NCAC) to evaluate these alternative preparation routes. This evaluation showed that alternative certification programs are effective in bringing quality individuals into teaching positions that otherwise would not likely enter the profession. Only $20 \%$ of individuals who entered teaching through Mississippi's alternate routes say they would have gone back to college and completed a traditional education program in order to become a certified 
teacher if the alternate route program had not existed. These routes are a viable way to bring talented individuals into teaching, and the evaluation found that having multiple models of alternative teacher preparation not only works well in Mississippi, it is favored by all groups over having just one centralized alternate route in the state.

Currently, about half of Mississippi's teachers come from alternate route certification, and according to the Clarion-Ledger (2008), "This is the first year the number of teachers certified through alternate routes outpaced the number of traditionally certified teachers." Even with this increase in alternate route certified teachers, there is still a significant shortage of teachers in the state of Mississippi.

\section{Learning and Educating through Alternative Programs (LEAP)}

Learning and Educating through Alternative Programs (LEAP), a Transition to Teaching grant funded through the United States Department of Education, was proposed by faculty in the College of Education (COE) at Mississippi State University (MSU) - Starkville and the MSU-Meridian Division of Education in conjunction with the Mississippi Department of Education (MDE) and 42 partnering high-need local education agencies (LEAs), to address the critical teacher shortage problem in the state of Mississippi. The program was approved in May of 2009.

Faculty and staff working with the LEAP program seek to recruit and retain non-traditional professionals and recent college graduates to teach in high-need LEAs through a state approved alternative route to teacher certification. The goals of the LEAP program are to implement a program that will: 1 ) Launch a statewide search for participants eligible for an alternative route education graduate degree; 2) Provide an alternative route for certification in secondary education for highly qualified midcareer professionals; 3) Assist participants through a first year teacher mentoring program; and 4) Reduce the severe teacher shortage identified across the state of Mississippi, which includes teachers teaching out of their field of certification and teaching by noncertified personnel.

The LEAP program curriculum is structured to provide rigorous and high quality academic training and fieldwork in order to thoroughly prepare participants for positions in high need classrooms. The COE, where the LEAP program is housed, is accredited by the National Council for Accreditation of Teacher Education and by the Southern Association of Colleges and Schools. In addition, each content area is required to meet rigorous program standards established by each specialty program area. These include the National Council of Teachers of English, National Council of Teachers of Mathematics, National Science Teachers Association, and National Council for the Social Studies, National Association for Sport and Physical Education, National Association of Music, and the International Society for Technology in Education.

LEAP faculty and staff at MSU work with this five-year, multifaceted program to expand the number of alternate route secondary teachers certified for the state of Mississippi. Since the implementation of the LEAP program, the COE secondary faculty have worked to approve the coursework so that the alternate route program could extend the certification program to include distance education classes to not only assist with recruitment but to better serve the highly qualified mid-career professionals and the recent college graduates who can assist with the reduction of the teacher shortage in Mississippi. MSU faculty and staff working with LEAP also continue to focus on recruiting, training, and retaining alternate route teachers for critically understaffed positions in high-need schools throughout the state.

LEAP applicants must meet the following admission requirements: hold a bachelor's degree or higher; have a 2.75 minimum GPA; take the Graduate Record Examination (GRE); provide a 40 hours' work experience form and three letters of recommendation; complete a successful interview; pass the PRAXIS I Reading, Writing, and Mathematics examination; and pass the PRAXIS II examination in the subject area where licensure will be obtained. Applicants must have at least 21 hours in the subject area the applicant will be seeking certification in with at least a 2.75 QPA on the 21 hours and with no grade less than a $\mathrm{C}$, which are requirements by MDE for highly qualified status. If the applicant has not completed 21 hours of course work in the content area, he/she will be required to complete the balance of the 21 hours of content in addition to the 36-hour MAT-S program of study.

LEAP, a 36-credit hour program leading to a Master of Arts in Teaching - Secondary (MAT-S) degree, incorporates academic coursework, classroom internship, and mentoring. LEAP, which provides a comprehensive program of study for participants to obtain a degree and licensure in secondary education, allows participants to work with faculty and staff to plan a timeline that is best for them as they teach and complete the program of study. Although participants can complete the program of study in as little as 14 months, LEAP faculty and staff have found that it is most beneficial 
to work with individual participants to customize the time frame for completion of the program. The LEAP program integrates coursework and field experiences, is adaptable to participants' learning needs, and meets the requirements for an initial three-year licensure. After completion of the dimension courses (teaching internship), participants are eligible for the five-year renewable license. After completing of the program of study, LEAP teachers receive an AA (Master's) degree and licensure. The curriculum plan for the LEAP program has been developed by the MSU COE faculty to incorporate all required classes for teacher certification at the secondary level.

Each LEAP participant can receive as much as $\$ 5,000$ in scholarship funds with the understanding that he/she will complete three years of teaching (service) within a LEAP partner LEA. In addition, each LEAP participant receives a laptop to be used during the completion of the program. Participants also receive additional assistance and mentoring from university supervisors and assigned mentors and assistance as they seek employment with the partner LEAs.

The LEAP faculty and staff, which serves all areas of the state through the COE on the MSU Starkville campus and the Division of Education on the MSU Meridian campus, are working with LEAP seek to certify 35 new teachers per year with a total of at least 175 new teachers over the five-year grant period.

\section{Training, Delivery, and Timeline for Full Certification}

LEAP provides a comprehensive program of study for non-traditional students to obtain a degree and/or licensure in secondary education (Grades 712). Key elements of the LEAP curriculum include: 1) coursework that can be completed in 14 months but programs of study are based on participant needs; and 2) a mentoring program for the participants.

The timeline for teacher degree completion and /or credentialing through the LEAP program means that new teachers can enter the classroom after completing the first summer cohort. LEAP participants are required to choose a subject and complete the education requirements for the MAT-S alternate route degree program or requirements for licensure in their particular area.

6.1. Ensuring Teachers are Highly Qualified: Participants must pass the required PRAXIS exams in their area of specialization, and are required to pursue a graduate degree or certification-only coursework as part of their training. Participants meet with the
LEAP faculty and staff to determine their individual timelines. Participants, monitored by the LEAP faculty and staff, re assigned university supervisors and mentors. In addition student must have a minimum of 21 undergraduate hours in the academic area that they are planning to teach (biology, English, history, math, etc..).

6.2. Placement: LEAP participants seek employment in LEAs where there is a need for certified teachers. LEAP faculty and staff work with superintendents and principals in partner LEAs to assist the LEAP participants as they seek employment. Since recruiting efforts are made to recruit highly qualified mid-career professionals (including highly qualified paraprofessionals) from the communities of the partner LEAs, the LEAP participants often go back to their own communities to teach.

6.3. Induction: After acceptance into the program, LEAP participants meet with the LEAP staff to determine the timeframe for completing the initial coursework in order to receive the three year initial license. LEAP faculty and staff work with each participant to assist with the career transition into teaching.

\section{4 Required Coursework leading to teacher certification through LEAP (3 tracks)}

\subsubsection{Degree-Track:}

\section{Summer I:}

Measurement and Evaluation

Advanced Planning and Managing Learning

Integrating Technology for Meaningful Learning OR Advanced Methodologies in Middle and Secondary Schools

Fall:

Dimensions of Learning (Internship- 6 hours.)

Content Methods of Teaching

Spring:

Dimensions of Learning II (Internship II- 6 hours)

Teaching Reading in Secondary Schools

\section{Summer II:}

Principles of Effective Instruction Special Education in the Regular Classroom Middle and Secondary Curriculum

\subsubsection{Certification-Only Track:}




\section{Summer I:}

Measurement and Evaluation

Advanced Planning and Managing Learning

Fall:

Dimensions of Learning (Internship- 6 hours.)

Content Methods of Teaching

6.4.3. Special Education certification in collaboration with the Mississippi Department of Education's Teach Mississippi Institute:

\section{Summer I:}

Measurement and Evaluation

Advanced Planning and Managing Learning

Special Education in the Regular Classroom

\section{Fall:}

Dimensions of Learning (Internship - 6 hours.)

Content Methods of Teaching

\section{The First Two Years (2009-2011): Numbers, the Economy, and New Tracks for Certification}

The first two years were somewhat of a challenge, but the LEAP faculty and staff was resilient and worked to overcome these challenges. During year one, only 13 LEAP scholarships were awarded. However, during year two the numbers increased and 40 scholarships were awarded.

After year one, the program officer at the U.S. Department of Education acknowledged a need for a certification-only track as an option for recruiting participants for the LEAP program. With this approval, an option for a certification-only track was established. In addition, a special education track was approved in collaboration with the MDE's Teach Mississippi Institute. The addition of these new tracks was a helpful option for participants seeking teacher certification.

The retention rate for teachers that graduated through the LEAP Program was 96\% during the first two years. This rate is $4 \%$ higher than the projected rate. The LEAP faculty and staff currently have 60 students on scholarship and are working with our partner LEAs.

\section{Concerns: Failure to Recruit a High Number of Black Males}

During the first two years, the LEAP Program focused on recruitment and continues to recruit for the program. The largest group of participants in the LEAP program was female. LEAP faculty and staff are working to recruit more males by participating in national and international conferences, attending recruitment events in Mississippi school districts, working with the MSU office of recruitment, appearing on television and radio shows, and seeking support from partner LEAs.

\section{Future Studies in Regards to LEAP}

Future studies for the LEAP Program will include comparing and contrasting retention rates of LEAP program participants to non-LEAP alternate route participants.

\section{Conclusion}

Retaining highly qualified teachers after they are hired has been a stumbling block for many school districts, particularly high-need LEAs without significant resources. LEAP faculty and staff have developed partnerships with LEAs to assist in helping new teachers become sustainable teachers for the partner LEAs. The importance of the school administrator in retaining teachers cannot be ignored, and a key factor to ultimate program success is making connections with school faculty and staff will continue to work closely with LEAs to assist in retaining teachers graduating from the LEAP program.

\section{References}

[1] Betts, R., \& Danenberg, (2000), Equal Resources, Equal Outcomes? The Distribution of School Resources and Student Achievement in California. http://www.ppic.org/content/pubs/report/R_200JBR.p df.

[2] Darling-Hammond, Youngs, (2002). "Does Teacher Preparation Matter? Evidence about Teacher Certification, Teach for America, and Teacher Effectiveness. The Stanford Report. Retreived from: www.educationminnesota.org/.../3F49830E5AC9419 69C0038377E2B3A7A.ashx

[3] Dillon, S. (2007). Study compares Math and Science Scores with other countries. New York Times. 
http://www.nytimes.com/2007/11/14/education/14stu dents.html

[4] Ferguson, (1988). A Reflective Approach to the Methods Practicum.

http://jte.sagepub.com/content/40/2/36.abstract

[5] Fetler, M. (1997). Staffing Up and Dropping Out. Education Policy Analysis Archives. Vol. 5 (16). A peer-reviewed scholarly electronic journal available at http://epaa.asu.edu/

[6] National Assessment of Educational Progress (NAEP): The Nation's Report Card. Retrieved from: http://nces.ed.gov/nationsreportcard 